\title{
INTERNET OF THINGS OF ELECTRONIC SEAL BASE ON GPRS SHORT MESSAGE SERVICE AND THINGSPEAK
}

\author{
Irawati Dewi Syahwir ${ }^{1} *$, Agus Samsi ${ }^{2}$, Vera Firmansyah ${ }^{1}$, \\ Prasetyo Wibowo Yunanto ${ }^{3}$, Renanda Maheswara ${ }^{1}$, Navieda Putri Anggraeni ${ }^{1}$
}

\section{${ }^{1}$ Akademi Metrologi dan Instrumentasi, Indonesia}

${ }^{2}$ Faculty of Physics Engineering, Institut Teknologi Bandung, Indonesia

${ }^{3}$ Faculty of Engineering, Universitas Negeri Jakarta, Indonesia

*Corresponding Author Email: irawatidewisyahwir@gmail.com

Received: 29 June 2019

Revised: 14 November 2019

Accepted: 27 December 2019

Published: 31 December 2019

SPEKTRA: Jurnal Fisika dan Aplikasinya p-ISSN: 2541-3384

e-ISSN: 2541-3392

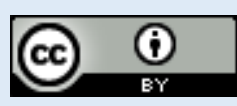

\begin{abstract}
The field of metrology is mainly legal metrology; seals are closely related to the guarantee or validity of a measuring instrument. Seals are designed so that it is not easy for other parties to open the seal. Seal damage must be identified as soon as possible. The application of the Internet of Things (IoT) is needed in the process of sending data in real-time. IoT technology can be applied to electronic seals to know and record the condition of the measuring device. Broken seals caused by irresponsible parties can cause losses to consumers and owners of measuring instruments. Electronic seals are expected to be able to detect seal damage caused by abuse of authority or fraud. The broken seal will send data to the server as well as SMS (Short Message Service) to the related party. Electronic seals can send damage data via SMS within 20 seconds with a success rate of $92 \%$ and sending data through the ThingSpeak web server within 40 seconds with a success rate of $82 \%$.
\end{abstract}

Keywords: internet of things, electronic seals, SMS, ThingSpeak 


\section{INTRODUCTION}

Based on Law No. 2 of 1981 concerning Legal Metrology, Metrology is the science of general measuring. The legal metrology is metrology that manages units of measurement, measurement methods, and measuring instruments for technical and regulatory requirements based on legal metrology laws for public assistance for things that are measured. Legal metrology always related to Verification and type of approval. All circulation of UTTP (The Weighing Measuring Instrument and Equipment) in Indonesia must go through the type permit procedure and the factory permit as a UTTP distribution permit abroad and domestically to be used in Indonesia [1].

After obtaining the marketing authorization, then the measuring instrument must be scolded, while for the extension period, the verification must be repeated. The Directorate of Legal Metrology handles all processes, the Ministry of Trade. The obligation of verification for each UTTP is regulated by the Minister of Trade Republic of Indonesia Regulation No. 67 of 2018 concerning Measuring Instruments, Weighing Measures, and Equipment that Must be Determined and Re-examined.

Not infrequently and not a few producers or traders try to skip or cheat the verification process to obtain higher profits. It is not uncommon for officers to commit fraud by making a fake sign so that the UTTP device used looks like it has been through an illumination procedure when inspected by a person who is being interviewed. To reduce these acts of cheating, the parties use the seal or stamp function as a guarantee of the validity of the UTTP tool that has been done the verification.

In the field of metrology, especially legal metrology, seals are closely related to the guarantee or validity of a measuring instrument. A seal in legal metrology is a sign that a UTTP has been hogged or re-bullied and stated using a CTT (Verification Sign). Based on the Regulation of the Minister of Trade of the Republic of Indonesia No. 68 of 2018 concerning verification UTTP, UTTP should have a specific period. Seal Signs are designed so that it is not easy for other parties to ruin the seal. Each UML user uses a CTT seal made of aluminum plates and aluminum wire in the UTTP device to lock the UTTP equipment after being hammered.

Another research about the internet of things is the Smartphone-Assisted Localization Algorithm where The smartphone stores the IoT device information in the response messages along with the message's signal strength and its position into a dedicated server (e.g., home gateway) for the localization [2-3]. Other reseach about the new symbolic model verifier (NuSMV) has been employed for the verification of the three schemes against the identified constraints. The verification results affirm the correctness and scalability of the models. The protocols are evaluated with performance metrics, such as the delivery ratio, latency, and overhead. Our results indicate significant improvement in performance compared to existing approaches [4-6].

One of the seals to be able to be monitored remotely by utilizing SMS (Short Message Service) and the Internet of Things (IoT). When the Seal is broken, the government can supervise UTTP by using SMS and Thingspeak so that the supervision of UTTP can run well [7-8]. The 
development of electronic seals is expected to be able to overcome the problems that occur in the field so that government programs in an orderly manner can be implemented.

\section{METHOD}

The design of the electronic seal uses several modules are GSM module (SIM800L), DC 5V Relay, Arduino Nano, Ni-MH Battery, Micro Current Amplifier Circuit, LED, DC Step-Down converter. Sending data using GPRS SMS and Thingspeak. The process of development also comparing with another studies about IoT applications [9-10].

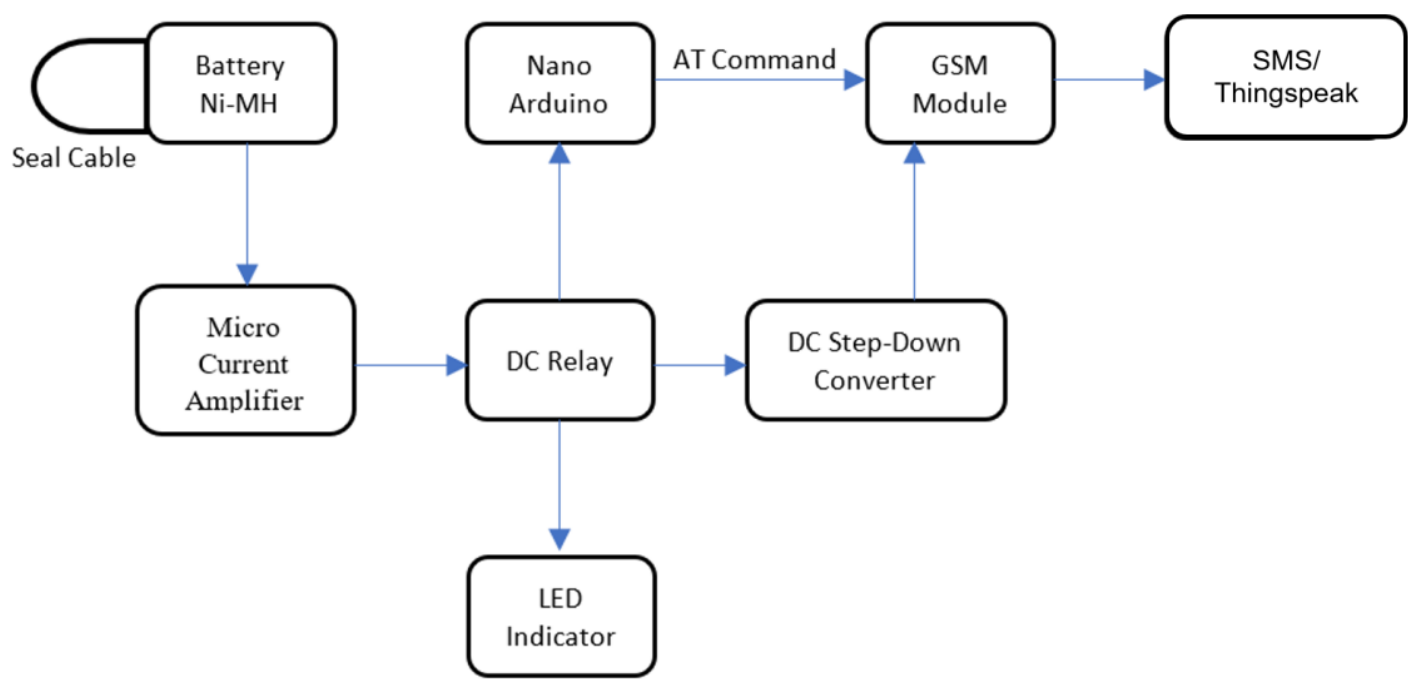

FIGURE 1. Electronic Seal Principles Block Diagram

FIGURE 1 shows the block diagram of the electronic seal working principle, where the working principle of the electronic seal was when the cable seal is broken, then the amplifier circuit would generate voltage to the relay, the relay would activate Arduino to instruct the GSM module to send data to perform certain functions. This relay would also activate the LED as an indicator if the seal was broken and would activate the DC step-down converter to reduce the relay output voltage to GSM operational voltage. For sending SMS and GPRS using data communication media on cellular network systems.

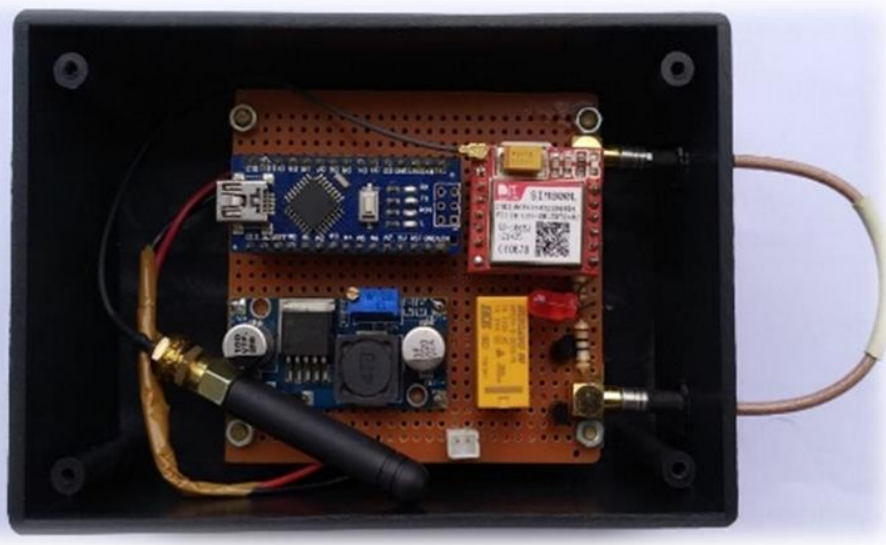

FIGURE 2. Prototype of Electronic Seal Development Results 
An electronic seal was a seal made with electronic components that can function to report automatically when the seal is damaged. Electronic seals are made to avoid violations or fraud that can be committed by unscrupulous officers and consumers. When electronic seals are damaged or tampered with by certain individuals, the seals will report the damage to the seal and data about the sealed item through sending SMS and GPRS data to Thingspeak's web server. FIGURE 2 shows the prototype image of the development of the Electronic Seal.

\section{RESULT AND DISCUSSION}

\section{The Result of Relay Test}

The results obtained indicate that the voltage required to activate the relay is $3.4 \mathrm{~V}$ with the required current of $25.52 \mathrm{~mA}$.

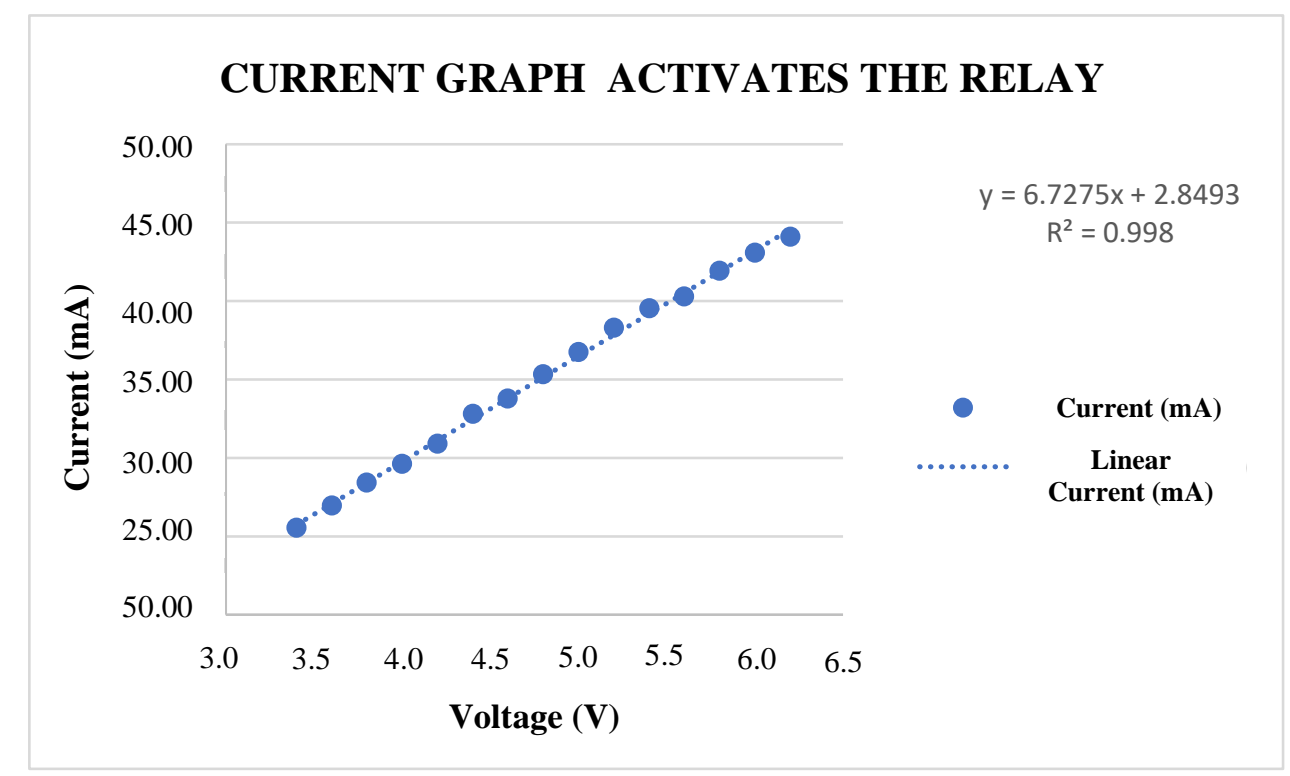

FIGURE 3. Regression Data for Relay Voltage and Current Measurement

Tests carried out by providing input with a linear increase so that the required current with a certain voltage value was known. FIGURE 3 shows the relationship of voltage to current needed to activate the relay was linear with a correlation coefficient of 0.998 and a linear equation obtained to determine the required current value with a certain voltage value. In the electronic seal prototype, a supply voltage of $6 \mathrm{~V}$ is used and the required current is $43.06 \mathrm{~mA}$. From this number, it can be seen that the number of transistors used in electronic seals with each amplification value is precisely used to amplify currents in micro-order under electronic seal standby conditions. 


\section{The Result of Micro Current Amplifier}

Current measurements made on the amplifier circuit produce values very fluctuating, so the data taken was the minimum and maximum values of the measured current. From the results of current measurements at each base and collector of each transistor. Transistor NPN (C828) $\mathrm{T} 1$ and T2 each have a gain of 346 and 318. If the $\beta$ value is compared with the $\beta$ value in the C828 transistor datasheet, transistors $\mathrm{T} 1$ and $\mathrm{T} 2$ can be categorized in type R transistors, namely transistors with a range of $\beta$ from 180 to 360 PNP transistor (C9012) T3 obtained a value of 4.25 . B value of the results of this test does not match the $\beta$ value in the $C 9012$ transistor datasheet which has a minimum value of 64 , because the current output of the transistor will adjust its electrical load, in this case, a relay that requires a current of $43.06 \mathrm{~mA}$ to be active. For transistor T3 because the output current is far less than the maximum capacity, the good $\beta$ value is the minimum value of T3 which is 4.25 to enable the relay.

For the measurement of the base current at T1 which is theoretically in the micro order, it cannot be measured accurately because measurements are made using a multimeter with an accuracy of $0.0001 \mu \mathrm{A}$. The output of the amplifier circuit is shown from the collector current measurements on the transistor T3 with a minimum average value of $49.83 \mathrm{~mA}$. In relay testing, to activate the relay at a voltage of $6 \mathrm{~V}$, a current of $43.06 \mathrm{~mA}$ is needed, so the amplification circuit created can amplify the current in the micro order to activate the relay. From this test, it was found that the transistor can amplify the current input on a micro Ampere (mA) scale. With a micro Ampere current input, a transistor can function itself as a current amplifier with a value of current reinforcement by $\beta$.

\section{The Result of Flow Consumption Testing}

The results of the current consumption used when the seal is broken, that the maximum current consumption of data transmission is $86.96 \mathrm{~mA}$, with the maximum current usage of the current amplifier of $12.65 \mathrm{~mA}$, from the current amplifier and Arduino Nano of $15.98 \mathrm{~mA}$, and the current amplifier and SIM800L of $19.95 \mathrm{~mA}$ In SIM800L standby conditions require a current of around 5-6 mA. When starting conditions (signal search) SIM800L requires a current of around 12-16 mA, while the LED requires a current of $19 \mathrm{~mA}$ when the signal search conditions. The total current needed is $86.96 \mathrm{~mA}$, in theory, the battery requires the power of $2700 \mathrm{mAh}$ so that the electronic seal can be used to send data 31 times.

\section{The Result of SIM800L GSM Module Testing}

The results on the sending time of the SIM800L module show the average value of standby time to get a signal was 23.80 seconds in the process of sending data to Thingspeak and 21.42 seconds in the process of sending an SMS. From the test results, the time required for the SIM800L module to reach the standby mode was relatively slow. This can be influenced by several factors, including the existence of the BTS tower (Base Transfer Station) and its reach to mobile phones, the farther the distance the SIM800L will be slower in searching for signals. Another factor was the voltage on the SIM800L must always be in the operating range of 3.7- 
4.2 V, when the voltage is below the voltage range, the SIM800L wouldn't reach standby mode. In the prototype, a Step-Down DC Regulator has been used to keep the input voltage in the operating range.

In sending data to Thingspeak, the average value of data reception time was 41.50 seconds, with a success rate of $92 \%$, from 50 attempts of sending data, 4 attempts failed. In sending SMS, the average value of receiving SMS time was 21.42 seconds, with a success rate of $82 \%$, from 50 attempts of sending data, 9 attempts failed. Sending SMS and sending data to Thingspeak requires a long time, but the prototype has used the latching function that was applied to the relay.

\section{CONCLUSION}

Based on the results of the work and testing were done on this final project, it can be concluded that An electronic seal prototype was made which can send seal damage reporting data.The delivery media of the electronic seal prototype was SMS and data to the ThingSpeak web server as an implementation of the Internet of Things (IoT) through the Arduino Nano microcontroller and the GSM SIM800L module.From the test results, the electronic seal prototype can report seal damage data within 20 seconds for sending SMS with a success rate of $92 \%$ and within 40 seconds for sending data to the ThingSpeak web server with a success rate of $82 \%$. For the future research is how to build a system seal with NorrowBand Internet of Things (NB-IoT).

\section{ACKNOWLEDGMENT}

This research was supported by Academy of Metrology Ministry of Trade, The Director of Legal Metrology Ministry of Trade.

\section{REFERENCES}

[1] Anonim, "Project Nodemcu membaca sensor DHT11 dengan THINGSPEAK", 2019.

[2] M. S. Aziis, "Penghenti Dan Monitoring Infus Dengan Sistem Telemetri Berbasis Pada Android", 2018.

[3] A. Jeong, S. Yeon, T. Kim, H. Lee, S. M. Kim, S. C. Kim, "SALA: Smartphone-Assisted Localization Algorithm for Positioning Indoor IoT Devices", 2018.

[4] A. Ghosh, O. Khalid, R.N.B. Rais, A. Rehman, S.U.R. Malik, I. A. Khan, "Data offloading in IoT environments: modeling, analysis, and verification", 2019.

[5] N. Pathak, A. Bhandari, "Creating Smart IoT Applications”, 2018.

[6] E. Sultanow, A. Chircu, “ A Review of IoT Technologies, Standards, Tools, Frameworks and Platforms", 2019. 
[7] Peraturan Menteri Perdagangan Republik Indonesia No 68 Tahun 2018. Tera dan Tera Ulang Alat UTTP. Jakarta, 2018.

[8] Undang-Undang Republik Indonesia No. 2 Tahun 1981. Metrologi Legal. Jakarta, 1981.

[9] K. Bharadwaj, R. Dhawan, M. K. Ray, \& P. Mahalakshmi, “ Wi-Fi-Based Low-Cost Monitoring of ECG and Temperature Parameters Using Arduino and ThingSpeak", In Advances in Systems, Control and Automation (pp. 637-646). Springer, Singapore, 2018.

[10] D. Barnard-Wills, “The potential for privacy seals in emerging technologies”, In Privacy and data protection seals (pp. 113-132). TMC Asser Press, The Hague, 2018. 
